\title{
Pairwise compatibility graphs
}

\author{
Muhammad Nur Yanhaona • \\ K.S.M. Tozammel Hossain • Md. Saidur Rahman
}

Published online: 5 December 2008

C) Korean Society for Computational and Applied Mathematics 2008

\section{Erratum to: J Appl Math Comput \\ DOI 10.1007/s12190-008-0204-7}

Unfortunately the third author's first name was abbreviated incorrectly. His correct name is Md. Saidur Rahman.

The online version of the original article can be found under doi:10.1007/s12190-008-0204-7.

M.N. Yanhaona ( $\varangle) \cdot$ K.S.M.T. Hossain · Md.S. Rahman

Department of Computer Science and Engineering, Bangladesh University of Engineering and Technology (BUET), Dhaka 1000, Bangladesh

e-mail: nur.yanhaona@gmail.com

K.S.M.T. Hossain

e-mail: tozammel@csebuet.org

Md.S. Rahman

e-mail: saidurrahman@cse.buet.ac.bd 